\title{
Emotions and Ethical Considerations of Women Undergoing IVF-Treatments
}

\author{
Sofia Kaliarnta · Jessica Nihlén-Fahlquist • \\ Sabine Roeser
}

(C) The Author(s) 2011. This article is published with open access at Springerlink.com

\begin{abstract}
Women who suffer from fertility issues often use in vitro fertilization (IVF) to realize their wish to have children. However, IVF has its own set of strict administration rules that leave the women physically and emotionally exhausted. Feeling alienated and frustrated, many IVF users turn to internet IVF-centered forums to share their stories and to find information and support. Based on the observation of Dutch and Greek IVF forums and a selection of 109 questionnaires from Dutch and Greek IVF forum users, we investigate the reasons why users of IVF participate in online communities centered on IVF, their need for emotional expression and support, and how they experience and use the information and support they receive through their participation in the online community. We argue that the emotional concerns expressed in such forums should be taken into account by health care ethics committees for IVF-related matters in order to promote more patient-oriented care and support for women going through IVF.
\end{abstract}

Keywords Emotions - In vitro fertilization (IVF) - Internet · Health care · Ethics · Infertility

\footnotetext{
S. Kaliarnta $(\bowtie) \cdot J$. Nihlén-Fahlquist

Philosophy Department, Faculty of Technology, Policy and Management, Delft University of Technology, P.O. Box 5015, 2600 GA Delft, The Netherlands

e-mail: S.Kaliarnta@tudelft.nl

J. Nihlén-Fahlquist

e-mail: j.a.nihlen-fahlquist@tudelft.nl

S. Roeser

Philosophy Department, Faculty of Technology, Policy and Management, Delft University of Technology, Jaffalaan 5, 2628 BX Delft, The Netherlands

e-mail: S.Roeser@tudelft.nl
} 


\section{Introduction}

Infertility is viewed worldwide by couples as "a tragedy which carries social, economic and psychological consequences". "It is estimated that $10 \%$ of the population globally suffers from infertility, which is generally defined as the inability to conceive after 1 year of unprotected intercourse (Gupta 2000, p. 339). In order to combat this phenomenon and give thousands of childless couples the chance of having a child, a whole array of assisted reproductive technologies has been developed in the past 30 years. The most renowned (and most used) method of assisted reproduction is in vitro fertilization (IVF), a revolutionary method in which egg cells are being fertilized by sperm in vitro, outside the woman's body. The process itself has high financial costs and demands a strict and intense regime of medication use, constant monitoring of hormone levels and intrusive procedures in order to retrieve eggs and after fertilization to place them back into the woman's uterus. This process can very quickly become mentally and physically taxing to the women who go through it, as well as to their partners; the social "stigma" of infertility makes it extremely daunting, or even impossible to get proper societal support, leaving them feeling alone, tired and frustrated.

Meanwhile, in the last few years, the internet has become an increasingly expanding source of medical information on any physical and mental health condition. Internet users go online to access medical records, get detailed information on symptoms, treatments, as well as means of prevention of severe illnesses and they come across other users who are willing to extend their knowledge and private stories about their own health ailments. The anonymity possible on the web has offered the chance for people with very sensitive and private health issues to open up and ask for relevant information, or to share their story with fellow patients online. This has led into the proliferation of online medical communities for a plethora of illnesses directed at patients, relatives and friends. This tendency has certainly included online communities especially for users of IVF, since they feel more secure and within the company of "fellow patients" who understand what they are going through.

The aim of this article is to investigate the reasons why users of IVF participate in online communities centered on IVF, their need for emotional expression and support and how they experience and appreciate the information and support they receive through the participation in the online community. We argue that the emotional concerns expressed in such forums should be taken into account by health care ethics committees for IVF-related matters.

\section{The Experience of Participants of IVF Forums}

This section discusses insights from an empirical study of the experience of participants in online IVF forums. Data has been gathered by questionnaires with participants of online medical communities which center on IVF, and in particular

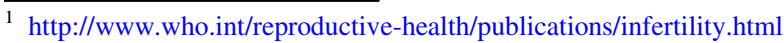


four Dutch and two Greek IVF online communities. Answers from the forum members themselves were deemed important in order to obtain triangulation, offer more insight and confirm findings from the observations. Of the six forums that were researched, one was completely private and accessible to members only, and two forums combined public sections with private ones. In order to be able to present the research results from the private forum, permission from the forum administrator was requested and obtained. The questionnaires yielded thirty-six responses from the two Greek IVF forums and seventy-three responses from the three Dutch forums. This information offers insights into the reasons to join IVF forums, as well as the way their participation in the forum was experienced and evaluated.

\section{Impact of IVF and Support from Others}

\section{Physical, Emotional and Relationship Impact of IVF}

An IVF treatment can have a tremendous impact on women: it is a very demanding physical process, with far-reaching effects on a woman's psychological well-being, her relationship with her partner, and her social environment. Emotions and expectations can run high and the whole process leaves the women exhausted and disheartened, as well as causing rifts in the relationship with her partner and social circle, as many of the women of the survey reported:

Emotionally I experienced mostly the breach of my privacy as annoying; constantly lying with your "lady bits" exposed and getting all kinds of treatments down there is no fun, no matter how kind and sympathetic the doctors are. That caused tension in the relationship, especially in the bedroom, in addition to the tension that the long waiting brings. Physically it was not pleasant, but it was doable with the right kind of anaesthesia.

(Dutch user)

Psychologically, the hormones make you very irritable and reacting strange to everything. Physically, there is water retention and great swelling in your belly. Financially, [costs] lots of money, and especially in the beginning of a young couple's new life, where they have many expenses. In the relationship with your partner, due to being more irritable from the hormones but also from the general situation, you have extra demands from your husband and he cannot understand that, poor him. Family: they all look at you questioningly every time they see you, [asking] 'are you pregnant? Did it work? Do not do this or do not do that...' Social circle: suddenly they are all interested to hear from you and suggest solutions; everybody expects to see you with a round belly and if that does not happen, they treat you as if you are ill.

(Greek user)

For other women, however, the experience of IVF was more mixed, since they did not gain only negative experiences, but also positive ones, like adopting a healthier lifestyle and getting closer to their partner: 
Emotionally it had a great impact; so much grief. Especially painful when everyone in your environment appears to get pregnant. Fortunately the relationship has not suffered. We have grown together stronger through this.

(Dutch user)

(It was) positive. I became stronger and overcame my phobias of needles and the sight of blood.

(Greek user)

It is quite understandable that not all women experience IVF in the same way; how one experiences a situation can depend on one's personal make-up, specific circumstances and personal situation. Another way to affect the overall experience is the knowledge and support of others. For women going through IVF, support of third parties can make a difference between a hard, yet positive learning experience, and a difficult and isolating one.

\section{Support from Family and Friends}

Going through IVF can be a very private and delicate issue; some of the couples that are busy with an IVF treatment prefer to keep this fact to themselves; others decide to share the news with selected members of their family and social circle. The attitude from the people who are informed about the process can vary greatly; some women report that they have encountered great disinterest and lack of understanding from the people close to them which, causes great disappointment and hurt feelings:

Family shows lack of understanding and disinterest, what you do not see does not exist, and just stick your head in the sand; it does not concern them, [these] are their words.

(Dutch user)

Other women on the other hand have reported positive reactions and support from their environment regarding IVF:

Everyone who knows [about IVF] has shown complete support.

(Greek user)

However, the majority of women have reported that even though many members of their family and friends have showed interest and concern and may be well meaning, they still do not know how exactly to approach them and show lack of understanding regarding the actual process of IVF and its actual impact, seemingly "saying all the wrong things at the wrong time":

Sometimes the in-laws seemed disinterested, but it turned out that it was a case of a difficult topic to breach, not wanting to be confronting.

(Dutch user) 
Relatives do not know about it; friends do try but if you do not have knowledge of IVF even as a concept, you do not always help even if you have every intention of doing so... I am satisfied because they are very interested.

(Greek user)

This attitude seems to be quite prevalent among friends and relatives of women who use IVF; the lack of adequate information about what IVF actually entails, as well as hesitation to tread on such a private matter can stilt communication between women who go through IVF and their social circle. The women have encountered a more general lack of understanding and empathy regarding IVF matters; this could signify that even though the general public has become more familiar with issues of infertility and assisted reproduction, there is still a lack of understanding of the full process concerning IVF, or the deep psychological and physical impact infertility can have on women. If anything, the cultural representations of IVF as "miraculous" and "normal" (Franklin 1997, p. 189) have resulted in public perceptions of IVF as a relatively easy and very successful way of combating infertility, which negates the complexity, difficulty and ambivalence of IVF and results in inadequate understanding and support of the women who go through such a process.

One reason why others may not support IVF patients to an adequate degree is ideas about what is natural. Fertility is usually considered an essential part of womanhood and to be infertile could be seen as unnatural or not normal. Similarly, IVF could be seen as going against nature. In an ethnographic study about IVF in Greece, it is suggested that families from rural villages may fear that, for example, their grandchild produced through IVF will be abnormal (Paxson 2003). These points to the need to investigate not only the emotional concerns of IVF patients, but the emotional concerns of people around IVF patients in order to increase their understanding and empathy with IVF patients.

\section{Reasons for Joining a Forum}

For many women, the main reason to join an IVF forum was to be able to share their story with others and to read their story in turn; to receive and give advice to women going through the same experience as they are:

In order to read the experiences of others and if you are in those two long waiting weeks, you want to express your frustration to others who are also trying to get through the time of waiting.

(Dutch user)

In order to exchange views with people that can commiserate and gain strength by listening to other couples' experiences.

(Greek user)

Another important reason for many of the women to join a forum was the feeling of recognition that they were among people which were also sharing the same experience and also the same feelings and questions, as well as the fact that the 
women in the forum could offer them understanding and support that people who have not experienced IVF could not.

It is comforting to know that there are other people that are going through the same or similar problems as you are and most of the times they are feeling the same. It makes you feel less alone.

(Greek user)

It can be deduced that women decide to join a forum about IVF in order to receive information, support, share their feelings, or feel that they are not alone in going through IVF; the forum is thought to provide them with equipment that they have difficulties in getting from their environment.

\section{Ways of Emotional Expression}

In the IVF forums, women report that they can allow themselves to express their thoughts in a very open and uncensored way; feelings of sadness, anger and frustration find an outlet, and sharing very private thoughts is not uncommon:

In your daily life people do become fed up with your story after a certain point. (They think) you should just learn to deal with it. In the forum you really can unload your frustration and also share your happiness and hope. In your daily life people do not really understand how much of an impact all this has.

(Dutch user)

One of the reasons why the women who participate in IVF forums are able to express themselves more freely is the feeling that they are among a group that understands them completely, has had the same experiences and so has deep knowledge of the feelings and thoughts concerning the whole process of IVF.

It is due to the fact that I have people with the same problem and goal 'opposite me', that will understand what I am going through, how I experience the attempts and the hardships that I am going through. They would not mock my longing for having a child.

(Greek user)

For some women, the anonymity offered by the forum was an important reason for their participation and free expression, since they could safely reveal their innermost thoughts and share feelings that their own social circle was not allowed to know.

It is easy to uncover your feelings to a stranger.

(Dutch user)

Anonymity, which has been considered as a negative factor in establishing real connections and relationships online, here is a liberating factor; the anonymous nature of such forums makes it easier to create conditions "to elicit highly intimate disclosures, especially important when dealing with sensitive health problems that discourage an open discussion" (Weisgerber 2004, p. 556). The women who participate in IVF forums make use of it in order to reveal their innermost thoughts and feelings. For these women, being members of a group which shares their 
experience, coupled with the anonymity that they enjoy online, is a great means of expressing themselves freely without fearing they will not be understood or that what they reveal will cause negative repercussions in their everyday life.

Gains from Forum Participation, Assessment of Positive and Negative Sides

\section{Benefits Gained}

When Greek and Dutch women are asked about what they feel they have gained from their participation in the IVF forums, the answer seems to be: a multitude of positive things. Most prominent ones include: feeling to be members of a tight community, acquiring invaluable medical education, support and hope for the future, as well as genuine emotional support and understanding.

I got understanding, support, and enthusiasm about going on, tremendous information which protects me from missteps. I feel for the results of the girls and feel that I have a big family.

(Greek user)

Participation in the forums, however, has also yielded some negative experiences as well, like becoming emotionally affected by the negative IVF results or pregnancy losses of other forum members and feeling that they should perhaps pursue more extended testing or therapy, since other members have done so.

When little babies are lost by mothers who have tried so hard to bring them into the world. It is a horrible feeling.

(Greek user)

Despite the negative experiences, however, the overwhelming majority of both the Greek and Dutch women have evaluated their forum participation as something positive, which has helped them through great difficulties and has enriched their lives by providing a significant amount of information, invaluable support and creating real connections with others.

Internet gives you a treasure of information (it is important though that you learn how to filter) and anonymous contacts with fellow 'sufferers' is extremely valuable. As far as I am concerned, forums like Freya fulfill an important societal role.

(Dutch user)

It has offered me many very good friends, since we now meet (offline). I have learned a lot of thing about IVF and medical tests; I have learned to discuss more freely my IVF attempts even with people outside the forum. The forum has made me feel proud for the hard fight that I have been giving and it has helped me many times when I feel weak to find my strength again and get back on my feet.

(Greek user)

It appears that the women participating in the IVF forums acquire a full range of experiences and emotions: a plethora of medical information that can help them in 
making important decisions about their treatment, but can also "overload" them and cause unnecessary worries; a place where they feel understood and can vent their thoughts and frustrations, but can also still experience negative emotions; a bond and connection with the other members that creates such strong empathy that it can cause them to experience deep sadness when other members face a negative outcome. As a forum member mentioned, "it is a society, with all the good and the bad that go with it."

These findings highlight how online medical communities can play a very important role in providing patients with information, help and emotional support. Their offer of online self-help and social support has been dubbed virtual community care (Burrows et al. 2000); it is a "terminological hybrid derived from the notion of a virtual community in cyberspace and the concept of community care in social policy” (p. 96).

\section{Including Emotional Concerns of IVF Users in Healthcare Ethics Committees}

The findings show the emotional impact IVF can have on its users. IVF is not just a medical solution to a biological problem. It is an extremely invasive procedure that is meant to solve a problem that has far-reaching personal, social and existential dimensions, and the procedure itself also has substantial impact on the lives and self-image of women and couples. The emotional concerns of IVF patients point to morally salient aspects of IVF treatments.

Emotions are often dismissed in decision making about medical and other technologies. They are seen as irrational distractions that blur the understanding of objective facts. However, recent emotion research shows that emotions are a source of practical rationality (Damasio 1994). Emotions are appraisals, they show us what we value and draw attention to evaluative aspects of the world (Scherer 1984; Frijda 1987; Lazarus 1991; Solomon 1993; Goldie 2000; Nussbaum 2001; Roberts 2003; Roeser 2011). Medical technologies such as IVF are not neutral tools; rather, they have an impact on the well-being of human beings, for better or worse. They carry risks and benefits with them. Assessing risks and benefits goes beyond measurable medical and technical data, it also involves moral and evaluative aspects (Fischhoff et al. 1981; Krimsky and Golding 1992; Shrader-Frechette 1991; Slovic 2000; Hansson 2004; Asveld and Roeser 2009) to which emotions provide privileged access (Kahan 2008; Roeser 2006, 2010).

The benefits of IVF are obvious, but hard fully to grasp without understanding the emotions of a couple whose wish to have a child is finally fulfilled. Furthermore, the risks of IVF go beyond medical complications. The risks of IVF also concern the impact they have on the psychological and social well-being of women and couples and the people who care for them. Without knowing the emotions of IVF users, it is impossible fully to comprehend the impact that IVF has on people, positively and negatively.

This suggests that it is highly important that the emotional concerns of women and men are taken into account in IVF treatment, health care and policy-making. IVF can be seen as a way to take control over nature and people who would otherwise not have children can possibly have them, which is a tremendous 
opportunity created by this technology. However, as we have seen, the negative effect of treatments and the emotional and psychological stress can be substantial. In order to make the most of IVF technology, emotions should be taken into consideration and attention should be paid to how such emotions can inform policy and health care. The most difficult part is how to do this in practice. The internet and social media are extremely important ways of expression for people undergoing IVF treatments. It is important to analyze emotional concerns expressed in such media. Of course the anonymity and privacy of the forums should not be threatened, but it should be possible to discern some general concerns that are shared by many IVF patients. The insights presented in this study (and possible follow-up studies) can inform professionals working with IVF patients about the experiences and emotions these patients undergo.

Reading about the happiness of a couple that finally gets a child due to IVF provides for a thorough understanding of the positive value this technology can have. On the other hand, reading about the suffering of women who undergo the strict regimen of IVF leads to compassion and can provide for support by partners, family and friends and to providing more pleasant conditions during the treatment by healthcare providers. It may lead to choosing slightly more expensive but less invasive treatments. Understanding the pain and disappointment of women or couples whose invasive and costly IVF-treatment does not provide them with a pregnancy, or where an IVF-induced pregnancy ends in a miscarriage, can lead to more compassionate care by healthcare providers and family and friends.

The emotions and concerns of the person who is a recipient of care should be taken into account by health care ethics committees. According to Held (2006), care is primarily a relation in which caretaker and cared-for share an interest in their mutual well-being. Held and Noddings (2002) argue that in order for a relation to be labeled care, the caring effort made by the caretaker has to be appreciated and acknowledged as care by the person that is being cared-for. The caring attitude has to be coupled with a concern for what the recipient needs and what she would define as care for her, as an individual. The focus should be on helping women and couples going through IVF to be able to navigate the "obstacle course" (Franklin 1997) of IVF by helping them to keep track of their emotional needs and offering support and a safe environment, especially in the painful moments that follow a failed IVF treatment. One has to particularly take into account the fact that women going through IVF are in a very vulnerable state, emotionally and physically, since they are going through a very demanding medical procedure that might be their only chance to achieve pregnancy and experience motherhood. This requires an understanding and empathetic environment between the IVF health care providers and their patients.

To analyze and include emotional concerns expressed in discussion forums in IVF-related health care could be a way to make IVF health care more compassionate and empathetic towards IVF patients. For example, a great source of disappointment for women going through IVF is the apparent lack of psychological support and guidance offered by the hospital or fertility center during the process of IVF. Despite the obvious usefulness of the forums, face to face contact with a professional psychologist can be considered as a potentially positive and valuable service. It would, therefore, be a prudent move of the health care ethics 
committee to propose that hospitals and fertility centers employ the services of a licensed psychologist or trained social workers, who will be able to have personal contact with IVF users and individually evaluate their needs.

Another source of uncertainty and frustration is the lack of full explanation of test results and diagnostic procedures, as well as insufficient transparency during the process of IVF from their doctors. Such behavior can cause doubts on the part of the IVF users who were not pleased by their treatment and expected more detailed explanation. Also, quite often the overly optimistic attitude of doctors regarding the positive outcome of an IVF treatment could cause great disappointment and distress to the IVF users after a cycle failure, since the same previously optimistic doctors were not able to offer a satisfying explanation after the failure. It is perhaps useful for the health care ethics committees to point out that doctors should not assume that their patients lack the necessary knowledge to process medical information, nor should they neglect to offer full explanation of the process around IVF, tests performed and IVF failure rates. Being open and honest with their patients will increase the feelings of trust and confidence of the patients and will lead to a better and fruitful cooperation.

Health care ethics committees could also attempt to offer a possible positive improvement of the information offered by the IVF forums by requesting that one or more doctors, specialized in IVF and fertility problems, should participate in IVF and dispense medical advice, which would provide the forum members with medically correct and reliable answers, or could volunteer to certify the correctness of the medical information and articles provided by the forum. The forum could also be divided into two sections, one that is accessible for everyone, including doctors, and one that is only accessible to forum members. For the forums, this could be a step in offering quality medical information, since many of the forum users, although grateful for the variety of medical information, appear to be unsure about the trustworthiness of the source and therefore, do not use the medical information offered in the forums. A certified doctor offering information in IVF forums would improve the trust and willingness of the users to consider the medical information and even incorporate it into their therapy plan. However, it should be noted that such a move could also have a negative impact on the willingness of the women to "expose" their problems and feelings if they feel that they have to "tone down" their frustration and disappointment, especially if they have had negative experiences with doctors in the past. Thus, before deciding to integrate the help of a doctor on an IVF forum, there should be a careful evaluation of the feelings and possible reactions of the forum members to such a possibility.

\section{Conclusion}

The emotional impact of infertility can be devastating for women, and even though the use of IVF can assist them in realizing their wish for a child, its strict administration and its physical and psychological impact can cause a new set of problems, not just for the women, but for their partners and social circle. Participating in IVF-centered forums is credited with offering women an enormous 
amount of information and support, helping them with taking important medical decisions and giving them a safe solace where they can express themselves among fellow IVF patients and feel understood and supported, in a way that perhaps compensates for the lack of support and understanding in their private lives.

These emotional needs and concerns expressed in IVF forums could be instrumentally used by health care ethics committees, in order to promote measures that can aid IVF health care professionals in offering more patient-oriented care and support for women going through IVF. Taking the emotional needs of IVF patients into account can help in creating a more balanced and supporting relationship between IVF users and their physicians, as well as providing them with information and support specifically tailored to their personal needs.

Acknowledgment The authors would like to thank the women members of Dutch and Greek IVF forums that kindly agreed to participate in the research by filling out the questionnaires.

Open Access This article is distributed under the terms of the Creative Commons Attribution Noncommercial License which permits any noncommercial use, distribution, and reproduction in any medium, provided the original author(s) and source are credited.

\section{Appendix}

Internet Forums Observed

\section{Dutch forums}

1. http://www.ivf-site.nl/Forum/

2. http://www.freya.nl/

3. http://www.stilverlangen.com/

4. http://www.ivfmoeders.nl/

\section{Greek forums}

1. http://www.ivfforums.gr/ivf/

2. http://www.hostingphpbb.com/forum/index.php

\section{English translation of the questionnaires}

1. Which forum are you coming from?

- Freya.nl

- Ivf-site.nl

- Ivfmoeders.nl

- Stilverlangen.com

- Other....

2. What is your age?

3. How many years have you been trying to conceive?

4. Infertility factor (female/male/both/unexplained). 
5. Have you had an IVF procedure done? (It can also be ICSI or FET (Frozen Embryo Transfer) If so, how often/how many times? If not, go on to question 7.

6. What impact did going through IVF have in your life? (i.e., on emotional, physical and/or financial aspect, on your relationship with your partner/family and environment).

7. Has the IVF treatment resulted in having a baby?

8. How did you discover this forum?

9. What was the reason(s) that made you decide to register and (actively as well as passively) participate in the forum?

10. Does your partner/relatives/friends know that you are a member of this forum?

11. Is your partner, a member of your family or a friend also a member of this forum?

12. How do you appropriate the information you get from the forum? (E.g., do you talk about it with your partner/friends/doctor?)

13. How do you evaluate the information you get from the forum (e.g., very useful, informative, neutral, meaningless etc.)?

14. Have you ever posted a topic regarding a medical issue (e.g., asking for information about the results of (blood) tests done or for information regarding medical terms etc.)? If not, you can skip question 14 .

15. If so, have you been satisfied by the answer?

16. As you satisfied by the support of your family/friends regarding the issue of IVF (or in trying to achieve pregnancy in general), or there is lack of understanding/interest?

17. How do you evaluate the behaviour of the other forum users and the general atmosphere in the forum?

18. Do you think that in the forum, you are being treated with more support/ understanding than in your everyday life?

19. Do you feel you can be more open/express yourself more freely in the forum? If so, what gives you that impression?

20. What do you think your participation in the forum has offered you? Have you experienced especially positive or negative things (and if so, what)?

21. Do you have any remaining remarks?

\section{References}

Asveld, L., \& Roeser, S. (Eds.). (2009). The ethics of technological risk. London: Earthscan.

Burrows, R., Nettleton, S., Pleace, N., Loader, B., \& Muncer, S. (2000). Virtual community care? Social policy and the emergence of computer mediated social support. Information Communication \& Society, 3(1), 95-121.

Damasio, A. (1994). Descartes' error. New York: Putnam.

Fischhoff, B., Lichtenstein, S., Slovic, S., Derby, S. L., \& Keeney, R. (1981). Acceptable risk. Cambridge: Cambridge University Press.

Franklin, S. (1997). Embodied progress: A cultural account of assisted conception. New York: Routledge.

Frijda, N. (1987). The emotions. Cambridge: Cambridge University Press.

Goldie, P. (2000). The emotions: A philosophical exploration. Oxford: Oxford University Press. 
Gupta, J. A. (2000). New reproductive technologies, women's health and autonomy: Freedom or dependency? New Delhi: Sage Publications.

Hansson, S. O. (2004). Philosophical perspectives on risk. Techné, 8, 10-35.

Held, V. (2006). The ethics of care: Personal, political and global. Oxford: Oxford University Press.

Kahan, D. M. (2008). Two conceptions of emotion in risk regulation. University of Pennsylvania Law Review, 156, 741-766.

Krimsky, S., \& Golding, D. (Eds.). (1992). Social theories of risk. Westport: Praeger Publishers.

Lazarus, R. (1991). Emotion and adaptation. New York: Oxford University Press.

Noddings, N. (2002). Starting at home: Caring and social policy. Berkeley: University of California Press.

Nussbaum, M. (2001). Upheavals of thought. Cambridge: Cambridge University Press.

Paxson, H. (2003). With or against nature? IVF, gender and reproductive agency in Athens, Greece. Social Science and Medicine, 56, 1853-1866.

Roberts, R. C. (2003). Emotions: An essay in aid of moral psychology. Cambridge: Cambridge University Press.

Roeser, S. (2006). The role of emotions in judging the moral acceptability of risks. Safety Science, 44, 689-700.

Roeser, S. (Ed.). (2010). Emotions and risky technologies. Dordrecht: Springer.

Roeser, S. (2011). Moral emotions and intuitions. Basingstoke: Palgrave Macmillan.

Scherer, K. R. (1984). On the nature and function of emotion: A component process approach. In K. R. Scherer \& P. Ekman (Eds.), Approaches to emotion (pp. 293-317). Hillsdale: Lawrence Erlbaum Associates.

Shrader-Frechette, K. (1991). Risk and rationality. Berkeley: University of California Press.

Slovic, P. (2000). The perception of risk. London: Earthscan.

Solomon, R. (1993). The passions: Emotions and the meaning of life. Indianapolis: Hackett.

Weisgerber, Corinne. (2004). Turning to the internet for help on sensitive medical problems. Information Communication \& Society, 7(4), 554-557. 